\title{
Green Synthesis of Silver Nanoparticles Using Panax Ginseng Root Extract for the Detection of $\mathrm{Hg}^{2+}$
}

\author{
Chandrakant Tagad, ${ }^{1,2 \#}$ Hyo Hyun Seo, ${ }^{3 \#}$ Rucha Tongaonkar, ${ }^{2}$ Yeong Wook Yu, ${ }^{4}$ \\ Jeong Hun Lee, ${ }^{3}$ Medini Dingre, ${ }^{2}$ Atul Kulkarni, ${ }^{5}$ Hassan Fouad, ${ }^{6,7}$ \\ Shafeeque Ahmed Ansari, ${ }^{8 *}$ and Sang Hyun $\mathrm{Moh}^{3,4^{* *}}$ \\ ${ }^{1}$ Department of Chemistry, Savitribai Phule Pune University, Pune 411007, India \\ ${ }^{2}$ Biochemical Research Division, GGENEX, Pune 411021, India \\ ${ }^{3}$ Anti-aging Research Institute of BIO-FD\&C Co. Ltd., Incheon 460810, South Korea \\ ${ }^{4} \mathrm{HuGeX}$ Co. Ltd., Gyeonggi-do 462100, South Korea \\ ${ }^{5}$ Nanoparticle Technology Lab, Sungkyunkwan University, Suwon 440746, South Korea \\ ${ }^{6}$ Department of Applied Medical Science, Riyadh Community College, King Saud University, \\ Riyadh 11437, Saudi Arabia \\ ${ }^{7}$ Biomedical Engineering Department, Faculty of Engineering, Helwan University, Helwan 11792, Egypt \\ ${ }^{8}$ Centre for Interdisciplinary Research in Basic Sciences, Jamia Millia Islamia, New Delhi 110025, India
}

(Received September 23, 2016; accepted November 28, 2016)

Keywords: green synthesis, Panax ginseng, silver nanoparticles, mercury ion detection, green extract

Exploring biomaterials/molecules as a reducing/capping agent for the synthesis of metal nanoparticles has set a new trend in green nanotechnology with improved environmental safety. Herein, a facile, one-pot, and green synthesis of silver nanoparticles (AgNPs) was achieved using Panax ginseng root extract that was obtained from the root powder as a cost-effective and environmentfriendly biomaterial. Optical, functional, and morphological characteristics of the synthesized AgNPs were determined using ultraviolet-visible (UV-vis), Fourier transform infrared (FTIR) spectrophotometers, transmission electron microscopy (TEM), and atomic force microscopy (AFM). The synthesized AgNPs were used for the detection of $\mathrm{Hg}^{2+}$ by obtaining the absorption spectrum of the compound as a function of $\mathrm{Hg}^{2+}$ concentration, which resulted in a decrease in absorption peak intensity with a slight blue shift. The AgNP solution decolored upon dissolution due to the formation of an $\mathrm{Ag}-\mathrm{Hg}$ amalgam. The sensing characteristics were found to be linear when tested from $10 \mu \mathrm{M}$ to $1 \mathrm{mM} \mathrm{Hg}^{2+}$ concentration and the detection limit was estimated as $5 \mu \mathrm{M}$. To check the selectivity of the sensor towards $\mathrm{Hg}^{2+}$, the sensor response was measured for different heavy metals such as $\mathrm{K}^{+}, \mathrm{Na}^{+}, \mathrm{Cu}^{2+}, \mathrm{Ni}^{2+}, \mathrm{Ca}^{2+}, \mathrm{Zn}^{2+}, \mathrm{Mg}^{2+}$, and $\mathrm{Mn}^{2+}$, at $10 \mathrm{mM}$ concentrations.

\section{Introduction}

With parallel research on several materials including metals, metal oxides, biomaterials, and polymers, metallic nanoparticles have been continuously investigated owing to their electronic, optical, magnetic, catalytic, and other physical/chemical properties. ${ }^{(1,2)}$ Owing to their unusual properties, they have widespread applications as a simple and sensitive tool for the detection of chemical species.(3) With recent technological advances in synthesis, the morphologies of nanoparticles can be finely tailored/synthesized with suitable chemical compounds to be made

*Corresponding author: e-mail: saansari@jmi.ac.in

**Corresponding author: e-mail: shmoh@biofdnc.com

\#Contributed equally

http://dx.doi.org/10.18494/SAM.2017.1475

ISSN 0914-4935 C MYU K.K. 
suitable to designated applications, ${ }^{(4-7)}$ either by controlling the chemical or physical propeties/ synthesis methods. However, such methods use chemicals as reducing agents, which are toxic and pose serious threats to the environment and biological systems. ${ }^{(1,8)}$ To address such threats, the green chemistry method has been found as a safe and widely accepted method, with features such as simplicity, cost-effectiveness, environment-friendiness, and biocompatibility with biomedical and pharmaceutical applications. ${ }^{(9,10)}$ Silver, a known material for several applications, has been synthesized in nanosize using several physical and chemical methods and well reported in the literature. Similarly, the green or environment-friendly synthesis of silver nanoparticles (AgNPs) has been reported using seed/plant extracts, microorganisms, plant latex, and biopolymers. ${ }^{(1-14)}$ The quest for finding other effective and user-friendly route/source of green synthesis/material made researchers find and explore other plants that have medicinal values.

Panax ginseng, also known as Asian or Korean ginseng, is a well-known and popular herbal medicinal plant. ${ }^{(15,16)}$ The ginseng roots' active components are ginsenosides, which are found to exhibit a variety of medicinal properties including anti-inflammatory, anticancer, and antioxidant properties. They are also found to improve psychological well-being, immune functions, and diabetic conditions.(15) Applications of Panax ginseng root extract for the synthesis of metal nanoparticles have been reported elsewhere. ${ }^{(17)}$

Therefore, in this study, an attempt is made for the synthesis of highly stable colloidal AgNPs using the root extract of Panax ginseng. To the best of our knowledge, this is the first report on the hydrothermal synthesis of AgNPs using the root extract of Panax ginseng with the added advantages of rapid synthesis, low particle size, and narrow size distribution.

Mercury, a heavy metal, is known as a toxic pollutant being emitted from coal-burning power plants, fossil fuel emissions, incandescent lights, batteries, ritualistic practices using mercury, and the incineration of medical waste. ${ }^{(18)}$ Mercury toxicity is a serious threat to living beings. It is a highly toxic element and can affect the human nervous system and cause severe damage to the brain, kidney, heart, lungs, and immune system. ${ }^{(18-20)}$ Because of this, the development of efficient sensors for the detection of mercury is of considerable interest. Several sensors based on electrochemical measurements, color, and fluorescence detection have been reported. ${ }^{(18,21-23)}$ Sophisticated instruments such as inductively coupled plasma mass spectrometer (ICP-MS), ${ }^{(24)}$ inductively coupled plasma optical emission spectrometer (ICP-OES), ${ }^{(25)}$ cold vapor atomic absorption spectrometer (CVAAS), ${ }^{(26)}$ stripping voltammeter, ${ }^{(27)}$ and atomic fluorescence spectrometer (AFS) ${ }^{(28)}$ are being used for the analysis of $\mathrm{Hg}^{2+}$. Aside from their high sensitivity and selectivity for the detection of $\mathrm{Hg}^{2+}$, these instruments are highly expensive and nonportable, sample preparation is time-consuming, and trained personnel are required for their operation. To overcome these limitations and to avoid complicated instrumentation, several methods based on colorimetry and probes of noble metals have been developed for the easy detection of $\mathrm{Hg}^{2+} \cdot(18,20,21,29,30)$

In this study, the one-pot, simple, and rapid green synthesis of highly stable and colloidal AgNPs has been achieved using Panax ginseng root extract as a reducing and capping agent. The synthesized AgNPs were investigated for their structural and functional properties and used as a material for the detection of $\mathrm{Hg}^{2+}$ based on the dissolution of AgNPs and the formation of $\mathrm{Ag}-\mathrm{Hg}$ amalgam. 


\section{Experimental Methods}

\subsection{Materials}

Silver nitrate $\left(\mathrm{AgNO}_{3}, \mathrm{AR}\right.$ grade) was procured from Sisco Res. Lab., India. Panax ginseng root powder was purchased from BIO-FD\&C Co., Ltd., Republic of Korea. The root powder was used to obtain the extract and used as reducing agent. Deionized water was used for preparing all the solutions required in the experiments.

\subsection{Silver nanoparticles synthesis}

For AgNP synthesis, $0.2 \mathrm{~g}$ of Panax ginseng root powder was added to $100 \mathrm{ml}$ of deionized water and boiled for $20 \mathrm{~min}$. The solution was allowed to cool and filtered to remove insoluble impurities. The above solution of Panax ginseng root powder and $1 \mathrm{mM} \mathrm{AgNO}_{3}$ solution were mixed in varying proportions $(4: 1,3: 1,2: 1$, and $1: 1 \mathrm{v} / \mathrm{v})$ and the resultant reaction mixture was autoclaved for $30 \mathrm{~min}$ (optimized) at $120^{\circ} \mathrm{C}$ and a pressure of $15 \mathrm{psi}$. A schematic of the AgNP synthesis process is shown in Fig. 1.

The effects of different parameters such as time, concentration of precursor, concentration of reducing and capping agent, and $\mathrm{pH}$ of the extract have been studied as reported by us for the other biomaterials. ${ }^{(10)}$ The effect of $\mathrm{AgNO}_{3}$ concentration on $\mathrm{AgNP}$ synthesis was ascertained

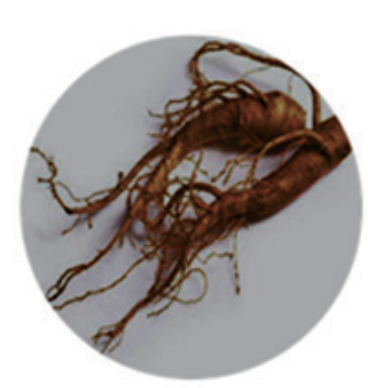

P. ginseng roots

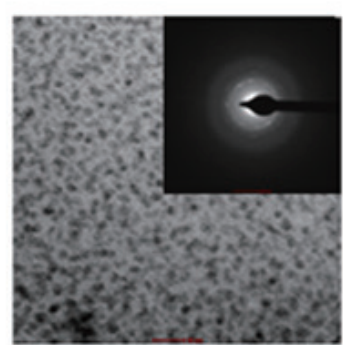

TEM analysis of AgNPs

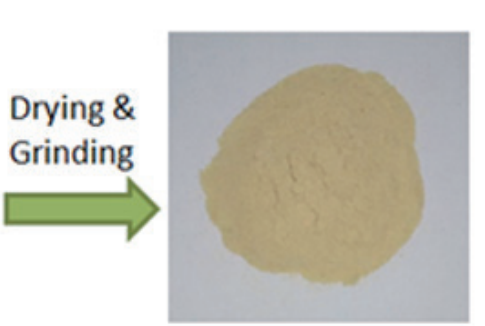

P. ginseng root powder

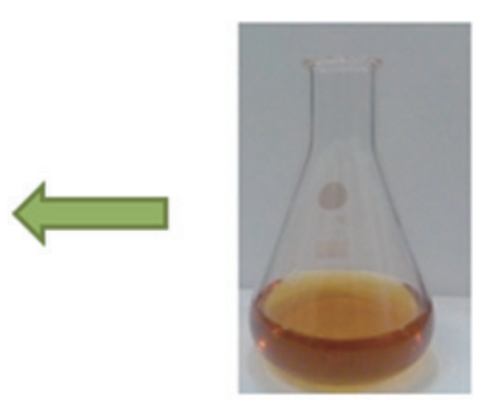

AgNp Colloidal Solution

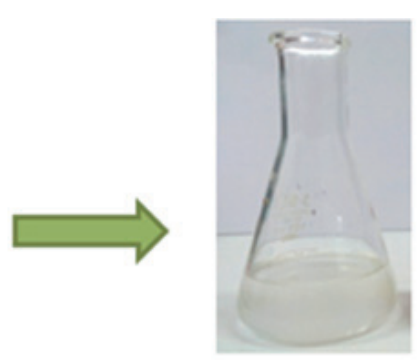

Root extract $+\mathrm{AgNO}_{3}$

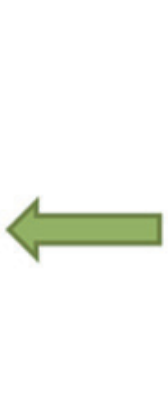

Autoclaving at $120^{\circ} \mathrm{C}$ and 15 psi pressure

Fig. 1. (Color online) Schematic presentation of synthesis of AgNPs from Panax ginseng root powder. 
by conducting an autoclaved reaction at different amounts of $\mathrm{AgNO}_{3}(1-5 \mathrm{mM})$ where the concentration of Panax ginseng root extract was kept constant at $0.2 \%(\mathrm{w} / \mathrm{v})$. The effect of various concentrations of Panax ginseng root extract $(0.04-0.2 \% \mathrm{w} / \mathrm{v})$ on the synthesis of AgNPs was also studied while keeping the $\mathrm{AgNO}_{3}$ concentration fixed as $1 \mathrm{mM}$.

To study the effect of the $\mathrm{pH}$ of the Panax ginseng root extract on AgNP synthesis, the $\mathrm{pH}$ of the Panax ginseng root extract solution was adjusted to $6,8,10$, and 12 using $0.5 \mathrm{M} \mathrm{HCl}$ and $0.5 \mathrm{M}$ $\mathrm{NaOH}$. Furthermore, a $5 \mathrm{ml}$ solution prepared with $1 \mathrm{mM} \mathrm{AgNO}_{3}$ was then added to $20 \mathrm{ml}$ of the Panax ginseng root extract solutions of different $\mathrm{pH}$ values and the reaction mixture was autoclaved for $30 \mathrm{~min}$ at $120^{\circ} \mathrm{C}$ and a pressure of $15 \mathrm{psi}$.

\subsection{Characterization}

Shimadzu's 1800 UV spectrophotometer was used to obtain absorption spectra with a resolution of $1 \mathrm{~nm}$ as a function of the reaction/synthesis time of AgNPs. For reference, the absorption spectrum of only the $\mathrm{AgNO}_{3}$ solution was also obtained without ginseng root extract. Structural and morphological characterizations of the AgNPs were carried out by using TEM (Philips CM200 instrument, $200 \mathrm{kV}$ ). A carbon-coated copper grid of 200 mesh size was coated with a drop of sample, air-dried, and then loaded in the TEM. AFM images were recorded using Nano Wizard ${ }^{\circledR}$ 3-AFM (JPK instruments) on a silicon substrate.

\subsection{AgNP-based optical detection of $\mathbf{H g}^{2+}$}

For the colorimetric detection of $\mathrm{Hg}^{2+}$, synthesized $\mathrm{AgNPs}$ were added to the different concentrations of $\mathrm{Hg}^{2+}$ in 1:1 (v/v) proportion. The resultant reaction mixture was mixed thoroughly and the absorption spectra were recorded after $10 \mathrm{~min}$ of reaction. To carry out selectivity studies, other possible contaminants were tested as above for each of $10 \mathrm{mM}$ concentration and ultravioletvisible (UV-vis) absorption spectra were recorded.

\section{Results and Discussion}

\subsection{Synthesis of AgNP}

The appearance of a characteristic dark yellow color and a single surface plasmon band in the form of a bell shape at $404 \mathrm{~nm}$ indicated the formation of AgNPs as the maximum absorbance is reported to be at $404 \mathrm{~nm}$. As a function of synthesis/reaction time, the absorbance was found to increase and a maximum was observed after a reaction time of $30 \mathrm{~min}$. Thus, the optimum reaction time for the synthesis of AgNPs was found to be $30 \mathrm{~min}$. Under the influence of high temperature and pressure, the rate of reduction of $\mathrm{Ag}^{+}$increases and therefore the rapid synthesis of AgNPs could be achieved. ${ }^{(12)}$

This is also because of the increased formation of AgNPs with the increase in the concentration of the reducing and capping agent. The higher the concentration of the reducing agent, the more the conversion of $\mathrm{Ag}^{+}$to $\mathrm{Ag}^{0}$, resulting in a concomitant increase in the absorption peak intensity at 404 $\mathrm{nm}$. Such concentration-dependent behavior of $\mathrm{AgNO}_{3}$ and reducing agent (ginseng in this case) in relation to the synthesis of AgNPs is in good agreement with previous reports. ${ }^{(14,31,32)}$ 
The absorption spectra (UV-vis) of AgNPs, synthesized with $0.2 \%$ (w/v) Panax ginseng extract and different concentrations of $\mathrm{AgNO}_{3}(1-5 \mathrm{mM})$, are depicted in Fig. 2(a). The absorption is found to increase with $\mathrm{AgNO}_{3}$ concentration, owing to the efficient reduction of $\mathrm{Ag}^{+}$to $\mathrm{Ag}^{0}$, which was found to be dependent on the $\mathrm{AgNO}_{3}$ concentration. It is expected that a large number of $\mathrm{Ag}^{+}$would be available for the ginseng extract to reduce $\mathrm{Ag}^{+}$into $\mathrm{Ag}^{0}$ with increasing $\mathrm{AgNO}_{3}$ concentration, resulting in a higher yield of AgNPs, which is responsible for the increase in the absorption peak intensity at $404 \mathrm{~nm}$.

Panax ginseng root extract was found to show reducing as well as capping ability to form a stable colloidal solution of AgNPs. The concentration of the reducing and capping agent is known to affect the size and thus the properties of AgNPs. The effect of Panax ginseng root extract on the synthesis of AgNPs has been studied by carrying out the reaction by varying the concentration of the Panax ginseng root extract while keeping the concentration of $\mathrm{AgNO}_{3}$ constant at $1 \mathrm{mM}$. Figure 2(b) shows a linear increase in the absorption peak intensity with increasing concentration of Panax

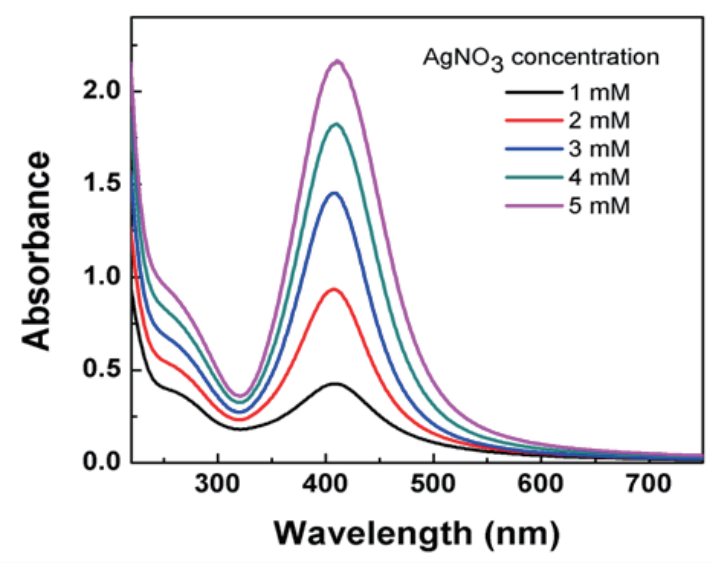

(a)

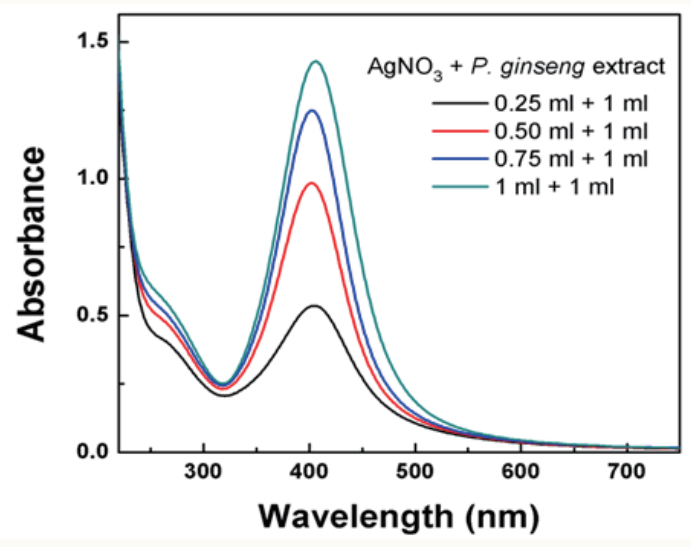

(c)

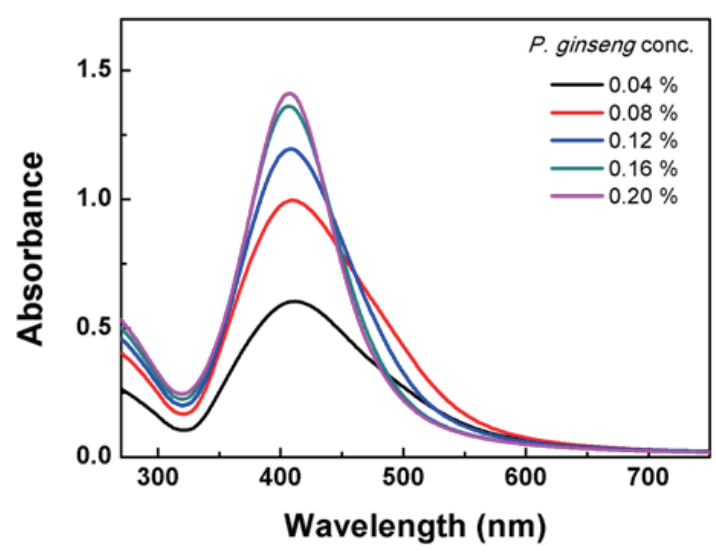

(b)

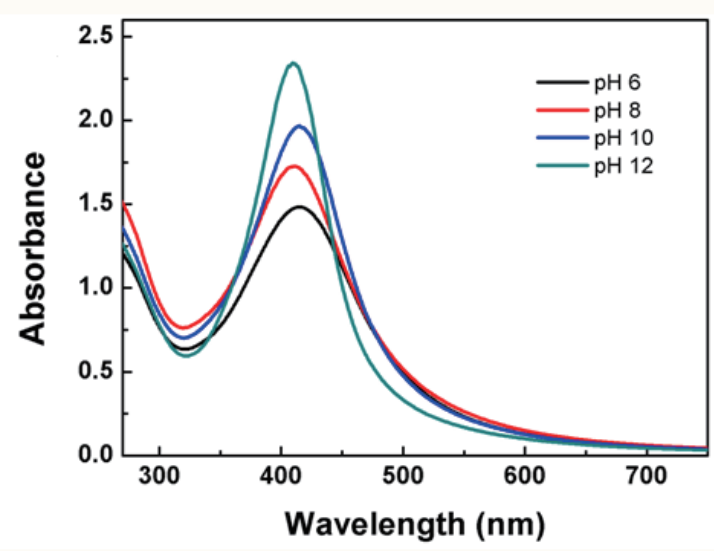

(d)

Fig. 2. (Color online) UV-vis absorption spectra of AgNPs synthesized at (a) different concentrations of $\mathrm{AgNO}_{3}$ (1-5 mM), where the Panax ginseng root extract concentration was $0.2 \%$, (b) different concentrations of Panax ginseng root extract $(0.04-2 \% \mathrm{w} / \mathrm{v})$, keeping $\mathrm{AgNO}_{3}$ concentration as $1 \mathrm{mM}$, and (c) varying proportions (v/v) of root extract and $\mathrm{AgNO}_{3}$. (d) Effect of $\mathrm{pH}$ of Panax ginseng root extract on synthesis of AgNPs. 
ginseng root extract, which is again an indication of the increased synthesis/yield of AgNPs with increasing concentration of reducing agent. Such concentration-dependent behavior of $\mathrm{AgNO}_{3}$ and the reducing agent (ginseng in this case) is in good agreement with previous reports. ${ }^{(14,31,32)}$ At higher concentrations of the root extract, the rate of nanoparticle synthesis was found to be excellent owing to the adequate availability of the reducing/capping agent for the efficient reduction of $\mathrm{Ag}^{+}$to $\mathrm{Ag}^{0}$. Similar observations were noted for the other biomaterials that are acting both as a reducing agent and a capping agent. ${ }^{(10,14)}$

Figure 2(c) shows the absorption spectra in the UV-vis range for AgNPs synthesized with $0.2 \%$ root extract and $1 \mathrm{mM} \mathrm{AgNO}_{3}$ in different proportions (v/v). An increase in surface plasmon absorption peak intensity with the increase in the proportion $(\mathrm{v} / \mathrm{v})$ of the root extract was observed since the amount of root powder in the total volume of the reaction mixture increases.

For estimating the effect of the $\mathrm{pH}$ of the Panax ginseng root extract solution on the synthesis of AgNPs, the AgNPs were synthesized with $0.2 \%$ Panax ginseng root extract of different $\mathrm{pH}$ values (6, 8,10 , and 12 adjusted with $1 \mathrm{M} \mathrm{HCl} / 0.5 \mathrm{M} \mathrm{NaOH}$ ) and $1 \mathrm{mM} \mathrm{Ag} \mathrm{NO}_{3}$. At acidic $\mathrm{pH}$, the reduction of $\mathrm{Ag}^{+}$to $\mathrm{Ag}^{0}$ is less favorable, as can be seen in Fig. 2(d). At alkaline pH, i.e., 8, 10, and 12, the peak intensity increased owing to the increased formation of AgNPs. The yellowish color (at pH 6) gradually changed to dark yellow and brown with increasing $\mathrm{pH}$ to 12 , which is in agreement with reported results. ${ }^{(32-34)}$ Even though a change in the color of the AgNP solution with the increase in the $\mathrm{pH}$ of the ginseng powder solution is seen, a peak shift is not observed, which is attributed to the variation in the dissociation constants (pKa) of functional groups on the biomass involved. ${ }^{(35)}$ In order to confirm the total conversion of $\mathrm{Ag}^{+}$to $\mathrm{AgNPs}$ (i.e., $\mathrm{Ag}^{0}$ ), a pinch of barium chloride $\left(\mathrm{BaCl}_{2}\right)$ was added to the synthesized $\mathrm{AgNPs}$ solution. Unreacted $\mathrm{Ag}^{+}$in the solution is expected to form white precipitate with $\mathrm{BaCl}_{2}$; however, no precipitates were observed, indicating the total conversion of $\mathrm{Ag}^{+}$to $\mathrm{Ag}^{0}$.

It is reported that at acidic $\mathrm{pH}$, silver nucleation is less resulting in lesser yield. ${ }^{(33)}$ With the increase in $\mathrm{pH}$, the ion density increases resulting in an increased number of nucleation regions owing to the larger availability of $\mathrm{OH}^{-}$ions. The rate of conversion of $\mathrm{Ag}^{+}$to $\mathrm{Ag}^{0}$ thus increases following the kinetics of silver deposition as reported elsewhere. ${ }^{(33)}$ Alqadi et al. reported the poor balance between the nucleation and the growth of AgNPs at acidic $\mathrm{pH}$ and increased reduction rate of $\mathrm{Ag}^{+}$to $\mathrm{Ag}^{0}$ at alkaline $\mathrm{pH}$, as can be evidenced by the increased absorption peak intensity with the increase in $\mathrm{pH} .{ }^{(34)}$ According to Birla et al., at alkaline $\mathrm{pH}$, the rate of synthesis of AgNPs and its stability are higher owing to the electrostatic repulsion arising from the adsorption of $\mathrm{OH}^{-}$ions on the surface of the AgNPs. ${ }^{(36)}$

The morphologies of the AgNPs were investigated using AFM and TEM. Figure 3 shows 2D AFM images of AgNPs at different magnification scales. The particle size of the AgNPs ranged from 4 to $20 \mathrm{~nm}$. The topographical image of the AgNPs in particular bright spots indicated distinct nanoparticles mostly spherical in shape. TEM observation [Fig. 4(a)] showed spherical particles of less than $20 \mathrm{~nm}$. The bright circular rings seen in the SAED pattern are assigned to (111), (200), (220), and (311), indicating a face-centered cubic (fcc) crystalline structure of the synthesized AgNPs [Fig. $4(\mathrm{~b})]$.

The Fourier transform infrared (FTIR) spectra showed a strong peak at $3640 \mathrm{~cm}^{-1}$, which was assigned to the stretching vibrations of the $\mathrm{O}-\mathrm{H}$ group in ginseng. A broad $\mathrm{O}-\mathrm{H}$ band was observed for AgNPs synthesized with ginseng in comparison with that of ginseng (without AgNPs), which can be attributed to the interaction of the AgNPs with the hydroxyl groups of the biomolecules present in the ginseng root powder. ${ }^{(37,38)}$ The FTIR spectra of the ginseng showed a peak at 

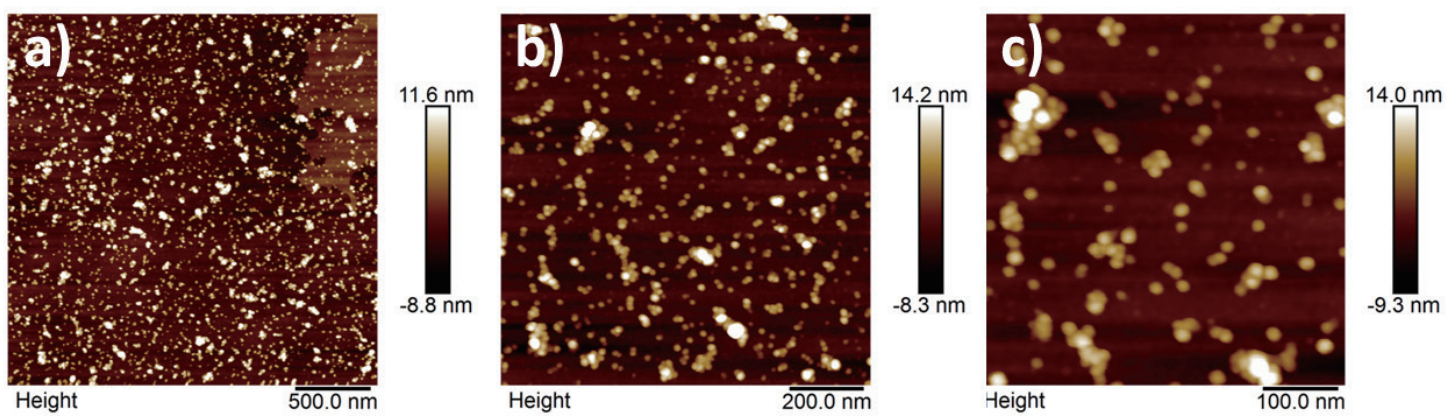

Fig. 3. (Color online) AFM analysis of AgNPs synthesized by autoclaving a reaction mixture containing $0.2 \%$ Panax ginseng root extract and $1 \mathrm{mM} \mathrm{AgNO}_{3}$ in 4:1 v/v proportion. (a)-(c) are AFM images analyzed at 500, 200, and $100 \mathrm{~nm}$ magnification scales, respectively.
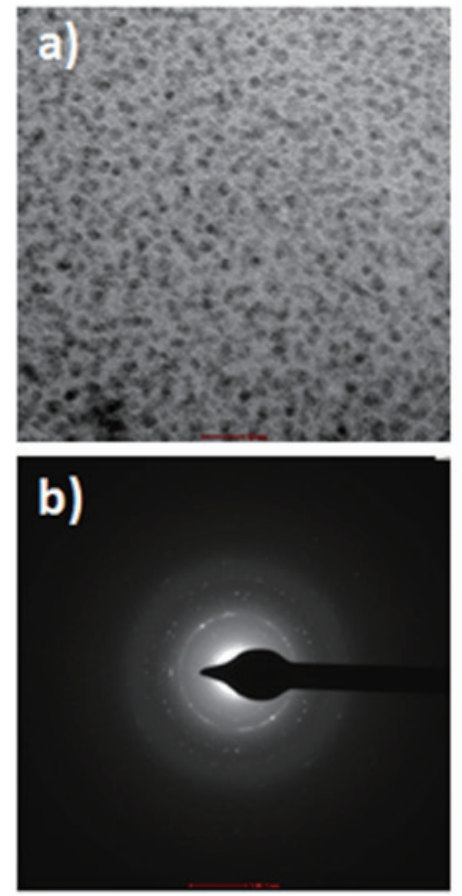
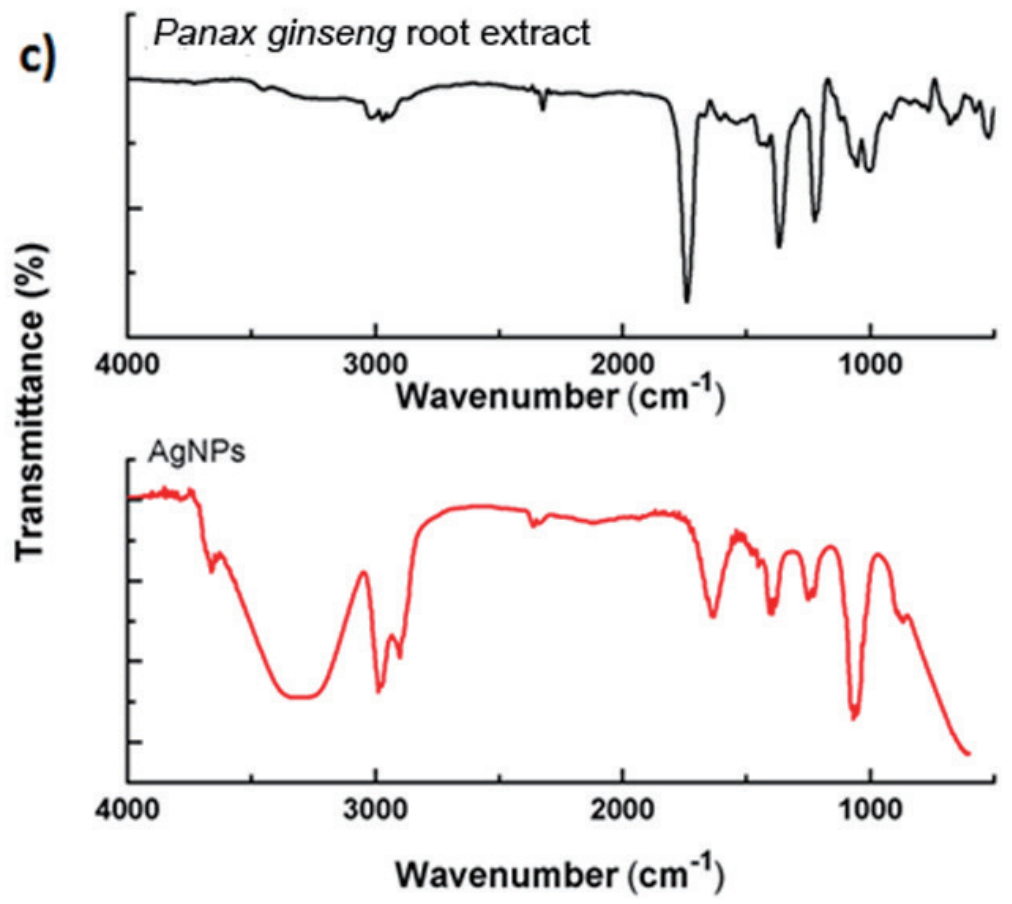

Fig. 4. (Color online) (a) TEM analysis, (b) SAED pattern, and (c) FTIR analysis of AgNPs synthesized using $0.2 \%$ Panax ginseng root extract and $1 \mathrm{mM} \mathrm{AgNO}_{3}$ in 4:1 v/v proportion.

$1740 \mathrm{~cm}^{-1}$, due to the carbonyl stretching vibrations of the aldehyde. ${ }^{(12,39)}$ The decrease in peak intensity at $1740 \mathrm{~cm}^{-1}$ and the increase in peak intensity at 1640 and $1407 \mathrm{~cm}^{-1}$ (for symmetric and asymmetric - $\mathrm{COO}$ stretching vibrations, respectively) of ginseng-stabilized AgNPs indicate the significant role of $-\mathrm{CHO}$ in the reduction of $\mathrm{Ag}^{+} .{ }^{(12,39)}$ A peak at $2988 \mathrm{~cm}^{-1}$ was assigned to the stretching vibrations of $\mathrm{C}-\mathrm{H}$ in methyl and methylene groups. ${ }^{(38,40)} 1065 \mathrm{~cm}^{-1}$ was assigned to the bending vibrations of $\mathrm{C}-\mathrm{C}-\mathrm{O}$ or $\mathrm{C}-\mathrm{C}-\mathrm{OH} .{ }^{(38)}$ A shift of frequencies was observed for ginsengAgNPs as compared with ginseng, clearly indicating the potential role of ginseng root powder as a reducing and capping agent for the synthesis of AgNPs. 


\subsection{AgNP-based detection of $\mathbf{H g}^{2+}$}

Figure 5(a) shows the sensor response for varying concentrations of $\mathrm{Hg}^{2+}$ where the absorption peak intensity decreases with a slight blue shift because of the $\mathrm{Hg}^{2+}$-mediated oxidation of AgNPs, which decolorized the AgNP colloidal solution. It has been reported that in the presence of the AgNP colloidal solution, the radiolysis of $\mathrm{Hg}^{2+}$ will lead to the mercury capping (reduced $\mathrm{Hg}^{0}$ ) on the AgNP, with a moderate peak broadening and a blue shift of the band/peak. ${ }^{(21)}$ The variation of peak intensity at $404 \mathrm{~nm}$ with respect to the concentration of $\mathrm{Hg}^{2+}$ is shown in the inset of Fig. 5(b). The AgNP-based sensor was found to show a linear response in the range of $10 \mu \mathrm{M}$ to $1 \mathrm{mM} \mathrm{Hg}^{2+}$ concentration with the detection limit of $5 \mu \mathrm{M}$. The decrease in the characteristic absorption peak intensity in the presence of $\mathrm{Hg}^{2+}$ may be attributed to (a) the reduction of $\mathrm{Hg}^{2+}$ to $\mathrm{Hg}^{0}$ via the partial oxidation of $\mathrm{Ag}^{0}$ and (b) the high affinity between $\mathrm{Ag}^{0}$ and $\mathrm{Hg}^{0}$. The reduced $\mathrm{Hg}^{0}$ gets deposited onto the $\mathrm{Ag}$ surface forming an alloy of $\mathrm{Hg}-\mathrm{Ag}$, which is reported as lumps in earlier reports with the help of scanning electron microscopy observation. ${ }^{(43,45)}$ The oxidation of AgNPs by $\mathrm{Hg}^{2+}$ therefore decreases the concentration of AgNPs, and decolors the solution resulting in decreased absorption peak intensity.

In this redox reaction, $\mathrm{Ag}^{0}$ is oxidized to $\mathrm{Ag}^{+}$with the concomitant reduction of $\mathrm{Hg}^{2+}$ to $\mathrm{Hg}^{0}$. Thus, the oxidation of AgNPs leads to the loss of its characteristic color and decrease in its UV-vis absorption peak intensity [Fig. 5(a)]. Since the variation in the standard electrode potential value of $\mathrm{Ag}^{+} / \mathrm{Ag}(E 0=0.79 \mathrm{~V})$ and $\mathrm{Hg}^{2+} / \mathrm{Hg}(E 0=0.85 \mathrm{~V})$ is very small, the fast redox reaction between the zero-valent $\mathrm{Ag}^{0}$ and the divalent $\mathrm{Hg}^{2+}$ would not be favorable. However, it is a well-established fact that the physical and chemical properties at nanoscale are far different from those of the bulk owing to the quantization effect. ${ }^{(39,41,42)}$ It is known that the redox potential of the $M^{X+} / M^{0}$ couple is very different from that of the corresponding $M^{X+} / M_{\text {metal }}$ couple. In this redox reaction, such unexpected rapid redox reaction between the zero-valent $\mathrm{Ag}^{0}$ and the divalent $\mathrm{Hg}^{2+}$ occurs owing to the

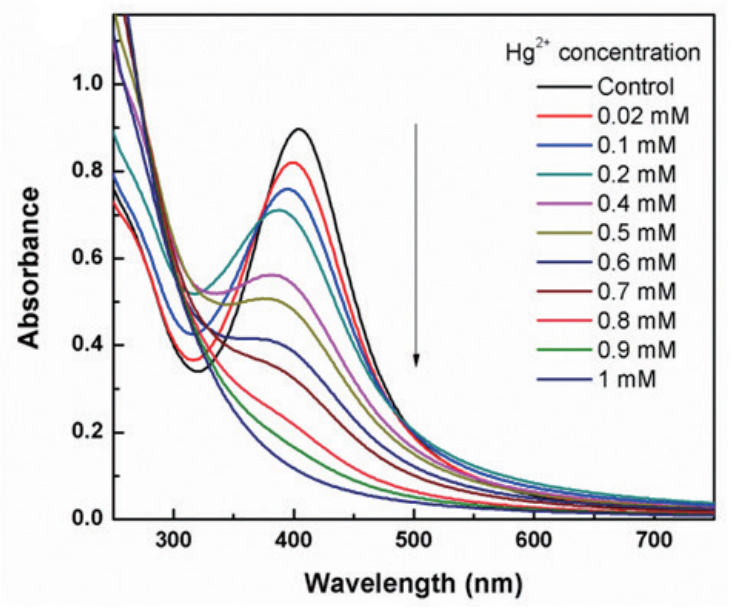

(a)

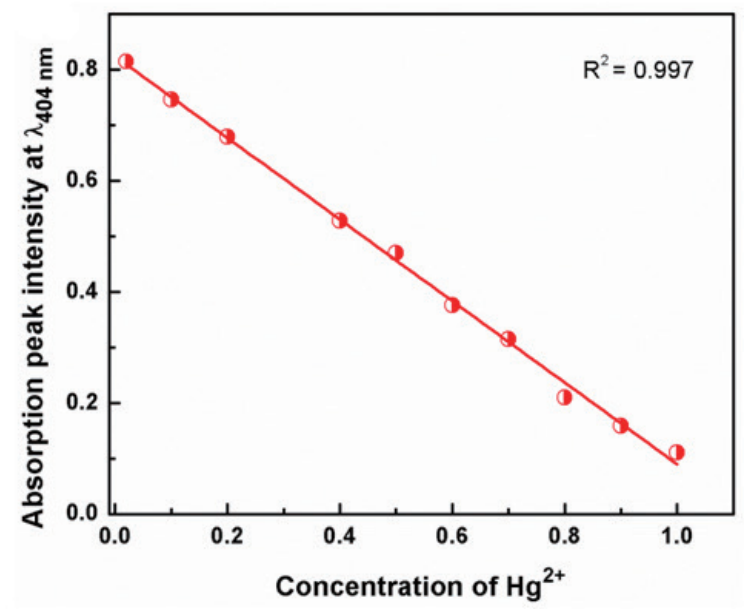

(b)

Fig. 5. (Color online) (a) UV-vis spectra of AgNPs with different concentrations of $\mathrm{Hg}^{2+}$. (b) Plot of absorption peak intensity at $404 \mathrm{~nm}$ as a function of $\mathrm{Hg}^{2+}$ concentration. 
nanoscale nature of AgNPs, which heightens the effective variation between the $\mathrm{Ag}^{+} / \mathrm{Ag}$ nano and $\mathrm{Hg}^{2+} / \mathrm{Hg}$ redox potentials and would favor the reduction of $\mathrm{Hg}^{2+}$ to $\mathrm{Hg}^{0}$ with the partial oxidation of $\mathrm{Ag}^{0} \cdot{ }^{(18,21,39,43-45)}$ Owing to the high affinity between $\mathrm{Ag}^{0}$ and $\mathrm{Hg}^{0}$, the reduced $\mathrm{Hg}^{0}$ gets deposited onto the Ag surface, resulting in the formation of the $\mathrm{Hg}-\mathrm{Ag}$ alloy. ${ }^{(18,21,43,44)}$ This further results in a decreased intensity and blue shift. ${ }^{(18,21,43,44)}$

To evaluate the degree of degradation of AgNPs due to $\mathrm{Hg}^{2+}$, a sensitivity factor $(S F)$ has been decided and calculated and $S F$ is calculated as

$$
\% S F=\frac{A_{0}-A_{1}}{A_{0}} \times 100
$$

where $A_{0}$ and $A_{1}$ are absorption peak intensities in the absence and presence of metal ions respectively. This was estimated from the plot of the intensity and concentration of $\mathrm{Hg}^{2+}$, shown as Fig. 6(a), which varies linearly with the increase in the $\mathrm{Hg}^{2+}$ concentration.

To check the selectivity of the sensor towards $\mathrm{Hg}^{2+}$, the sensor response was measured for different heavy metals such as $\mathrm{K}^{+}, \mathrm{Na}^{+}, \mathrm{Cu}^{2+}, \mathrm{Ni}^{2+}, \mathrm{Ca}^{2+}, \mathrm{Zn}^{2+}, \mathrm{Mg}^{2+}$, and $\mathrm{Mn}^{2+}$ each of $10 \mathrm{mM}$ concentration. Figure 6(b) shows the plot of the percent sensitivity factor for different metal ions. No significant change in the $\% S F$ is shown for $\mathrm{K}^{+}, \mathrm{Na}^{+}, \mathrm{Cu}^{2+}, \mathrm{Ni}^{2+}, \mathrm{Ca}^{2+}, \mathrm{Zn}^{2+}, \mathrm{Mg}^{2+}$, and $\mathrm{Mn}^{2+}$ even after 30 min of reaction, indicating the selectivity of the sensor towards $\mathrm{Hg}^{2+}$. The inset of Fig. 6(b) shows the color of the solution after the addition of different metal ions to the AgNP colloid. The complete loss of the characteristic color of AgNPs was observed in the presence of $\mathrm{Hg}^{2+}$, whereas no remarkable change in the color of AgNPs was noted in the presence of the other metal ions, indicating the selectivity of $\mathrm{Hg}^{2+}$ towards AgNPs.

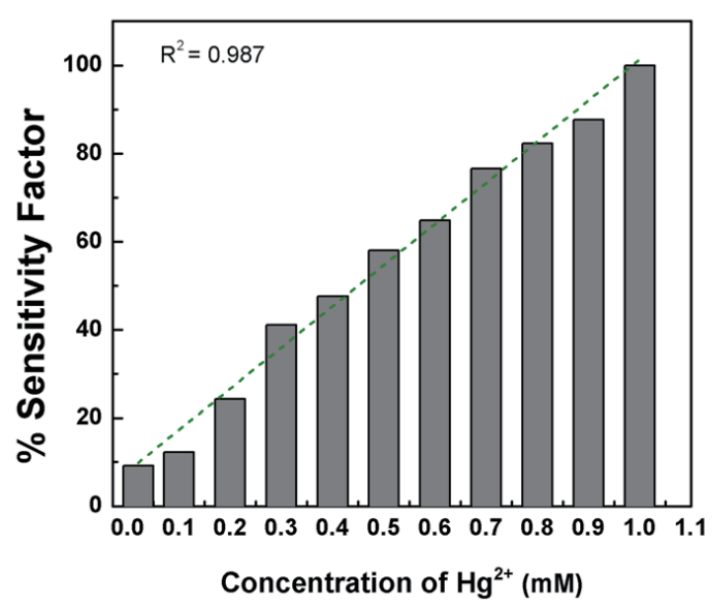

(a)

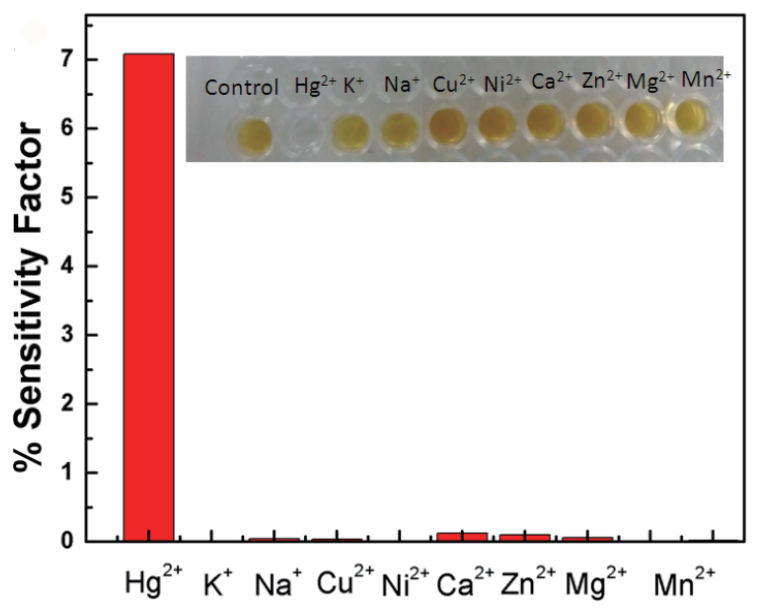

(b)

Fig. 6. (Color online) (a) Change in percent sensitivity factor as a function of different concentrations of $\mathrm{Hg}^{2+}$ and (b) plot of $\% S F$ for different metal ions, each of $10 \mathrm{mM}$ concentration. The inset of Fig. 6(b) shows changes in the characteristic color of AgNPs in the presence of different metal ions. 


\section{Conclusion}

In the present study, the facile, one-pot, rapid, and environment-friendly benign hydrothermal synthesis of AgNPs was achieved by using the extract of Panax ginseng root powder at various $\mathrm{pH}$ values. Furthermore, the synthesized AgNPs were used as a selective tool for the detection of $\mathrm{Hg}^{2+}$ over a wide range. AgNPs with ginseng extract were found to show a linear response in the range from $10 \mu \mathrm{M}$ to $1 \mathrm{mM} \mathrm{Hg}^{2+}$ with the minimum detection limit of $5 \mu \mathrm{M}$. This photometric detection of $\mathrm{Hg}^{2+}$ is simple, rapid, and can be miniaturized to have a portable system for the analysis of samples for the presence of $\mathrm{Hg}^{2+}$.

\section{Acknowledgements}

This research was supported by 'The Project of Conversion by the Past R\&D Results' through the Ministry of Trade, Industry and Energy (MOTIE) and the Korea Institute for the Advancement of Technology (KIAT) (N0001556, 2015). The authors would like to extend their sincere appreciation to the Deanship of Scientific Research at King Saud University for funding this research group (No. RG-1435-052).

\section{References}

1 H. Bar, D. K. Bhui, G. R. Sahoo, P. Sarkar, S. R. De, and A. Misra: Colloids Surf., A 339 (2009) 134.

2 G. A. Ozin: Adv. Mater. 4 (1992) 612.

3 A. Nimbalkar, C. K. Tagad, S. G. Sabharwal, A. Ravikumar, S. Gosavi, T. Kim, S. Zinjarde, and A. Kulkarni: Sensor Lett. 12 (2014) 1633.

4 L. Guo, Q. J. Huang, X. Y. Li, and S. H. Yang: Phys. Chem. Chem. Phys. 3 (2001) 1661.

5 E. C. Njagi, H. Huang, L. Stafford, H. Genuino, H. M. Galindo, J. B. Collins, G. E. Hoag, and S. L. Suib: Langmuir 27 (2011) 264.

6 H. Srikanth, R. Hajndl, C. Chirinos, J. Sanders, A. Sampath, and T. S. Sudarshan: Appl. Phys. Lett. 79 (2001) 3503.

7 Y. G. Sun, B. Mayers, T. Herricks, and Y. N. Xia: Nano Lett. 3 (2003) 955.

8 M. N. Nadagouda and R. S. Varma: Green Chem. 10 (2008) 859.

9 E. S. Abdel-Halim, M. H. El-Rafie, and S. S. Al-Deyab: Carbohydr. Polym. 85 (2011) 692.

10 C. K. Tagad, S. R. Dugasani, R. Aiyer, S. Park, A. Kulkarni, and S. Sabharwal: Sens. Actuators, B 183 (2013) 144.

11 V. K. Sharma, R. A. Yngard, and Y. Lin: Adv. Colloid Interface Sci. 145 (2009) 83.

12 C. K. Tagad, K. S. Rajdeo, A. Kulkarni, P. More, R. C. Aiyer, and S. Sabharwal: RSC Adv. 4 (2014) 24014.

13 J. Chen, J. Wang, X. Zhang, and Y. L. Jin: Mater. Chem. Phys. 108 (2008) 421.

14 Y. M. Mohan, K. M. Raju, K. Sambasivudu, S. Singh, and B. Sreedhar: J. Appl. Polym. Sci. 106 (2007) 3375.

15 D. Kiefer and T. Pantuso: Am. Fam. Physician 68 (2003) 1539.

16 H. R. Shin, J. Y. Kim, T. K. Yun, G. Morgan, and H. Vainio: Cancer Causes Control 11 (2000) 565.

17 P. Singh, Y. J. Kim, C. Wang, R. Mathiyalagan, M. E. Farh, and D. C. Yang: Artif. Cells Nanomed. Biotechnol. 44 (2016) 811.

18 K. Farhadi, M. Forough, R. Molaei, S. Hajizadeh, and A. Rafipour: Sens. Actuators, B 161 (2012) 880.

19 T. W. Clarkson, L. Magos, and G. J. Myers: N. Engl. J. Med. 349 (2003) 1731.

20 Y. Wang, F. Yang, and X. R. Yang: Biosens. Bioelectron. 25 (2010) 1994.

21 Y. J. Fan, Z. Liu, L. Wang, and J. H. Zhan: Nanoscale Res. Lett. 4 (2009) 1230.

22 L. Liu, G. X. Zhang, J. F. Xiang, D. Q. Zhang, and D. B. Zhu: Org. Lett. 10 (2008) 4581.

23 H. Yang, Z. G. Zhou, K. W. Huang, M. X. Yu, F. Y. Li, T. Yi, and C. H. Huang: Org. Lett. 9 (2007) 4729.

24 B. M. W. Fong, T. S. Siu, J. S. K. Lee, and S. Tam: J. Anal. Toxicol. 31 (2007) 281.

25 R. F. Suddendorf, J. O. Watts, and K. Boyer: J. Assoc. Off. Anal. Chem. 64 (1981) 1105.

26 Q. J. Yang, Q. Tan, K. Z. Zhou, K. L. Xu, and X. D. Hou: J. Anal. At. Spectrom. 20 (2005) 760. 
27 M. A. Nolan and S. P. Kounaves: Anal. Chem. 71 (1999) 3567.

28 Y. Gao, W. L. Yang, C. B. Zheng, X. D. Hou, and L. Wu: J. Anal. At. Spectrom. 26 (2011) 126.

29 M. A. Ahmed, N. Hasan, and S. Mohiuddin: ISRN Nanotechnology 2014 (2014) 5.

30 Y. Wang, F. Yang, and X. R. Yang: ACS Appl. Mater. Interfaces 2 (2010) 339.

31 M. M. H. Khalil, E. H. Ismail, K. Z. El-Baghdady, and D. Mohamed: Arab. J. Chem. 7 (2014) 1131.

32 C. Krishnaraj, R. Ramachandran, K. Mohan, and P. T. Kalaichelvan: Spectrochim. Acta Mol. Biomol. Spectrosc. 93 (2012) 95.

33 M. Rai and N. Duran (eds): Metal Nanoparticles in Microbiology (Springer-Verlag, Berlin, 2011).

34 M. K. Alqadi, O. A. A. Noqtah, F. Y. Alzoubi, J. Alzouby, and K. Aljarrah: Mater. Sci.-Poland 32 (2014) 107.

35 H. M. M. Ibrahim: J. Radiat. Res. Appl. Sci 8 (2015) 265.

36 S. S. Birla, S. C. Gaikwad, A. K. Gade, and M. K. Rai: Scientific World J. 2013 (2013) 796018.

37 A. Vanamudan and P. P. Sudhakar: Int. J. Biol. Macromol. 86 (2016) 262.

38 Y. X. Ji, Z. Y. Rao, J. L. Cui, H. Y. Bao, C. Y. Chen, C. Y. Shu, and J. R. Gong: J. Nanosci. Nanotechnol. 12 (2012) 6163.

39 L. Rastogi, R. B. Sashidhar, D. Karunasagar, and J. Arunachalam: Talanta 118 (2014) 111.

40 K. Leonard, B. Ahmmad, H. Okamura, and J. Kurawaki: Colloids Surf., B 82 (2011) 391.

41 C. deCointet, M. Mostafavi, J. Khatouri, and J. Belloni: J. Phys. Chem. B 101 (1997) 3512.

42 A. Henglein: Chem. Rev. 89 (1989) 1861.

43 L. Chen, X. L. Fu, W. H. Lu, and L. X. Chen: ACS Appl. Mater. Interfaces 5 (2013) 284.

44 K. Z. Kamali, A. Pandikumar, S. Jayabal, R. Ramaraj, H. N. Lim, B. H. Ong, C. S. D. Bien, Y. Y. Kee, and N. M. Huang: Microchim. Acta 183 (2016) 369.

45 N. Pradhan, A. Pal, and T. Pal: Colloids Surf., A 196 (2002) 247.

46 A. Jeevikaa and D. R. Shankarana: Mater. Res. Bull. 83 (2016) 48. 